\title{
CARDIOTHORACIC IMAGING
}

\section{Spot the mesh: Six-month follow-up}

David C. Reineke, MD, Bernhard Winkler, MD, Lars Englberger, MD, and Thierry P. Carrel, MD

We report the cases of 2 patients, 56 and 78 years old, who underwent coronary artery bypass grafting with the use of

From the Department of Cardiovascular Surgery, University Hospital Berne, Bern, Switzerland.

Disclosures: Lars Englberger reports consulting and lecture fees from Kips Bay and lecture fees from Medtronic. Thierry P. Carrel reports lectures fees from Edwards and Medtronic. The other authors have nothing to disclose with regard to commercial support

Received for publication Sept 2, 2014; revisions received Sept 18, 2014; accepted for publication Sept 21, 2014; available ahead of print Oct 16, 2014.

Address for reprints: David C. Reineke, MD, Department of Cardiovascular Surgery,

University Hospital Berne, Freiburgstrasse, 3010 Berne, Switzerland (E-mail: bernhard.winkler@insel.ch).

J Thorac Cardiovasc Surg 2015;149:388-9

$0022-5223 / \$ 36.00$

Copyright (c) 2015 by The American Association for Thoracic Surgery

http://dx.doi.org/10.1016/j.jtcvs.2014.09.064 a vein graft supported by the external vein mesh eSVS (Kips Bay Medical Inc, Minneapolis, Minn). Recent studies, such as the Synergy Between PCI With Taxus and Cardiac Surgery (SYNTAX) trial and Future Revascularization Evaluation in Patients with Diabetes Mellitus: Optimal Management of Multivessel Disease (FREEDOM) trial, have confirmed CABG to be the criterion standard in terms of survival and freedoms from myocardial infarction and the need for repeat revascularization. Despite evidence of additional survival benefit with bilateral internal thoracic arteries or any other second artery relative to a single internal thoracic artery, the saphenous vein is still the most commonly used second graft because of easy access and availability. Its main

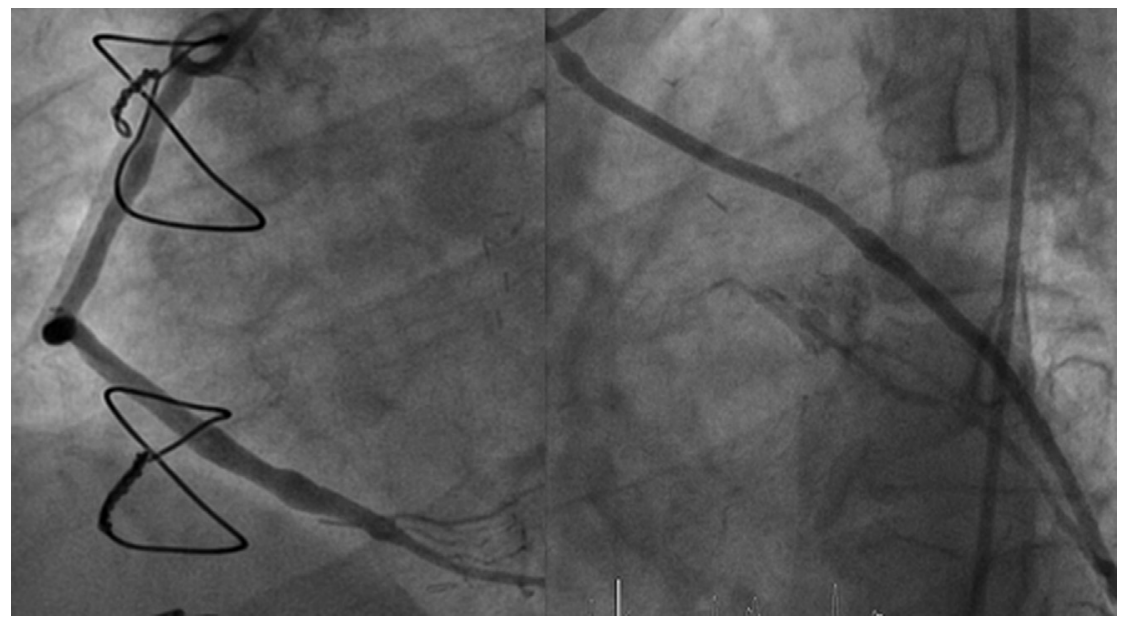

FIGURE 1. Two patients with "naked" vein grafts to the distal right coronary artery (left) and the circumflex artery.

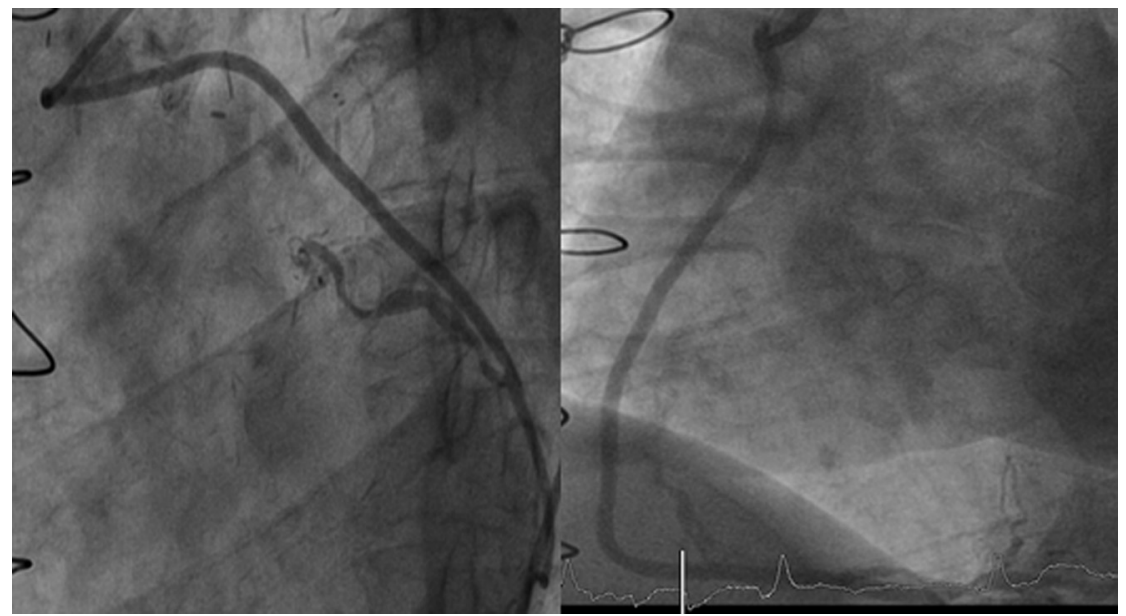

FIGURE 2. The same patients as in Figure 1 with externally supported grafts to the corresponding contralateral circumflex artery (left) and right coronary artery. 
disadvantage is its relatively poor long-term patency, with graft failure in as many as $20 \%$ of veins within the first year and $50 \%$ in 10 years. The mesh external vein support system eSVS, which to date is only available in Europe and not in the United States, is hypothesized to prevent premature vein graft failure after negative remodeling in the form of luminal enlargement, luminal irregularities, and intimal hyperplasia with thickening and stiffening of the vessel wall. Our series of impressive images (Figures 1 and 2) presents a 6-month follow-up of 2 patients in a randomized, controlled trial with the eSVS mesh device on one target vessel while leaving the vein to the second target vessel uncovered, with strikingly visible differences. 